\title{
MÚSICA VISUAL: DE LOS ÓRGANOS DE COLOR A LOS PRIMEROS ORDENADORES*
}

\author{
Carlos Manuel García Miragall \\ Universitat Politècnica de València. Dpto Sistemas Informáticos y Computación
}

\section{Francisco Sanmartín Piquer}

Universitat Politècnica de València. Dpto Pintura

\section{Trinidad Gracia Bensa}

Universitat Politècnica de València. Dpto Escultura

\section{Resumen}

La idea de obtener imágenes a partir de la música ha sido tratada a lo largo de los siglos; no como un movimiento independiente sino siempre dentro del contexto cultural y tecnológico de cada época. Este esfuerzo histórico se puede agrupar en lo que se ha venido a denominar Música Visual, Visualización del Sonido o Sonido Visual que fundamenta su naturaleza en la noción de sinestesia (Brougher 2005). El campo de la Música Visual siempre ha estado marcado por los medios tecnológicos involucrados en la creación de imágenes. En este trabajo realizamos una revisión histórica de algunas de las aportaciones que consideramos más relevantes centrándonos en las relaciones entre tecnología y arte. Nuestro repaso se inicia con las primeras intuiciones de los filósofos griegos de relacionar color y sonido y termina en los inicios de la era digital.

\section{VISUAL MUSIC: FROM THE COLOR ORGANS TO THE FIRST COMPUTERS}

\section{Abstract}

The idea of obtaining images from music has been treated over the centuries; not as an independent movement but always within the cultural and technological context of each era. This historical effort can be grouped into what has come to be called Visual Music, Sound Visualization or Visual Sound that bases its nature on the notion of synesthesia (Brougher 2005).The field of Visual Music has always been marked by the technological media involved in the creation of images. In this work, we conducted a historical review of some of the contributions that we consider most relevant, focusing on the relationship between technology and art. Our historical review begins with the first intuitions of the Greek philosophers to relate colour and sound and ends at the beginning of the digital age.

\section{Keywords: AUDIOVISUALIZATION; VISUAL MUSIC; DATA VISUALIZATION; SOFTWARE ART; EXPERIMENTAL SOUND}

\footnotetext{
García Miraga17, Carlos Manuel, Francisco Sanmartín Piquer \& Trinidad Gracia Bensa. "Música visual: De los órganos de color a los primeros ordenadores". AusArt 6 (1): 125-138. D0I: 10.1387/ausart.19463
}

\section{AUSART}




\section{INTRODUCCIÓN}

La idea de obtener imágenes a partir de la música ha sido tratada a lo largo de los siglos; no como un movimiento independiente sino siempre dentro del contexto cultural y tecnológico de cada época. Este esfuerzo histórico por buscar relaciones entre la música, el sonido y la imagen se puede agrupar en lo que se ha venido a denominar Música Visual, Visualización del Sonido o Sonido Visual que fundamenta su naturaleza en la noción de sinestesia (Brougher 2005).

Con independencia de la disciplina en la que nos encontremos la sinestesia en su sentido más amplio, se puede entender como una mixtura de impresiones que se perciben mediante distintos sentidos. De ahí que una persona sinestésica sea capaz de ver el sonido o escuchar un color. En el contexto de visualización del sonido, lo que se persigue es ver el sonido. Se trata de realizar una interpretación visual del sonido pero tomando como base principal el propio sonido, de la misma forma que lo haría una persona con capacidades sinestésicas. Las relaciones entre el sonido y la imagen o la luz a lo largo de la historia siempre han estado fusionadas con la idea de sinestesia.

En esa búsqueda de interpretar visualmente el sonido se han realizado multitud de propuestas, estando marcadas fundamentalmente por los medios tecnológicos involucrados en la creación de las imágenes. A grandes rasgos podemos trazar dos etapas históricas que hacia finales del siglo XX convergerán en los sistemas digitales. Por un lado, la tradición de órganos de color o instrumentos visuales, que se basa en realizar extensiones o modificaciones de instrumentos musicales con sistemas de proyección acoplados, capaces de establecer relaciones directas y en tiempo real entre el sonido y la imagen -el intérprete conforme toca la música va lanzando y generando las imágenes. Y por otro la tradición que surge alrededor del cine y el video analógico, estas tecnologías, con sus peculiaridades, permiten almacenar sonido e imagen sincronizada y procesar sus elementos.

Con la llegada del ordenador se produce la convergencia a un único dispositivo capaz de diseñar instrumentos de color, de fusionar el cine y el video en un único medio, de generar imagen sintética y sobre todo capaz de traducir la imagen y el sonido en un mismo lenguaje, el lenguaje de los números. En este contexto es cuando las posibilidades creativas de conexión entre el sonido y la imagen se manifiestan en su plenitud -sintetizadas en un lenguaje común. 
En lo que resta realizaremos un breve repaso histórico, a través de cinco etapas fundamentales que nos sirven de marco referencial: instrumentos mecánicos con capacidades visuales en la que se buscaba una representación de la sinestesia, almacenamiento del sonido y la imagen, generación sintética de imagen, popularización de las imágenes de la música, y finalmente terminaremos con la llegada de la era digital. Dentro de estas etapas vamos a resaltar tendencias y autores que estén más relacionados con los objetivos de esta revisión histórica. Fundamentalmente vamos a manejar dos ejes principales:

- La abstracción como corriente global de arte no figurativo y a nuestro entender estética natural del sonido.

- Imagen en movimiento generada a partir de propiedades directas del sonido o altamente influenciadas por éstas.

Para terminar el artículo presentaremos una recopilación de archivos web relacionados con el campo de la Música Visual y finalmente realizaremos una serie de conclusiones y trabajos futuros.

\section{BAJO LA IDEA DE SINESTESIA}

Los filósofos griegos Aristóteles y Pitágoras establecieron las primeras correlaciones entre las notas de la escala musical y el espectro del arco iris. Pero fue durante el siglo XVIII y el siglo XIX donde se sentaron las bases para el diseño de los primeros instrumentos de color, que se basaban fundamentalmente en las capacidades sinestésicas de sus autores. En la figura 1 se presentan algunas de las correspondencias propuestas por diversos autores.

El primer instrumento músico-visual se le atribuye al matemático francés Louis Bertrand Castel (Peacok 1988), que en 1730 construyó el Clavicornio Ocular. Básicamente era un clavicornio modificado y cuando se pulsaba una tecla se corría una cortina desvelando así una ventana de cristal coloreado, a través de la cual pasaba un haz de luz.

En una línea similar, Alexander Wallace Rimington en 1893 patentó un órgano de color (1912). Por otro lado, también destacamos el trabajo del pintor futurista Vladimir Baranoff que en 1916 construye una modificación de un piano que denomina Piano Optofónico, que generaba efectos ópticos que controla- 
ban la intensidad de la luz. El músico y pintor danés Thomas Wilfred construyó en 1919 el Clavilux, inspirado también en los órganos de color.

\begin{tabular}{|c|l|l|l|l|l|l|l|l|l|l|l|l|}
\hline Newton 1704 & Do & Do\# & Re & Re\# & Mi & Fa & Fa\# & Sol & Sol\# & La & La\# & Si \\
\hline Castell 1734 & & & & & & & & & & & & \\
\hline Field $1817^{15}$
\end{tabular}

Fig. 1. Tabla comparativa entre colores y sonidos

Mary Elizabeth Hallock-Greenewalt se distinguió por crear un arte que denominó Nourathar, entre 1916 y 1934 construyó el órgano de color que bautizaría como Sarabet. A diferencia de otros autores no estableció una correspondencia estricta entre colores y notas musicales, puesto que ella pensaba que estas relaciones debían reflejar la habilidad del intérprete.

La experimentación con instrumentos visuales-musicales se ha desarrollado hasta nuestros días, en la mayoría de los casos el piano se ha sustituido por interfaces basadas en sensores y los mecanismos físicos de generación de imágenes por sistemas informáticos. Actualmente muchas de las visualizaciones se basan en el protocolo de comunicación MIDI entre instrumentos (Malinowski 2016; Smith 1997; Sapp 2001). 
De esta primera etapa que llega hasta principios del siglo $\mathrm{XX}$, podemos concluir:

- Bajo la errónea idea que el sonido y la luz físicamente son iguales, el esfuerzo en la mayoría de instrumentos se centró en obtener una correspondencia unívoca entre notas musicales y colores. Esta correspondencia es subjetiva y se sustenta en las capacidades sinestésicas de los autores.

- El tiempo real está implícito en todas las propuestas, puesto que no se utilizan medios de almacenamiento sonoro, ni visual. Se busca que el espectador tenga una experiencia multisensorial. Es importante resaltar este hecho puesto que con la aparición de los medios audiovisuales como el cine o el vídeo, se pierde parte de este espíritu de performance.

- Al menos en las propuestas de Hallock-Greenewalt, Wilfred y Baranoff, el planteamiento de la visualización es diferente ya que proponen un nuevo arte de la luz. No se trata de realizar una correspondencia directa, sino de presentar un nuevo lenguaje basado en la luz y el sonido.

En Levin (2000), Peacock (1988), McDonnell (2007) y García (2016a) se realiza un estudio más detallado de las aportaciones históricas en este campo.

\section{ALMACENAMIENTO DEL SONIDO Y LA IMAGEN}

La aparición del cine se presenta como el medio idóneo al posibilitar la coexistencia sincronizada del sonido y la imagen. El nuevo medio además de capturar la realidad sonora y visual proporciona en si un nuevo lenguaje, el lenguaje del tiempo a través del cual desarrollar nuevas relaciones entre el sonido y la imagen. El movimiento de Abstracción, tanto en su vertiente plástica como cinematográfica, formaliza parte de su estética en los principios de composición musical (Kandinski [1911] 1996). El cine experimental abstracto y más en concreto lo que se ha venido a denominar Música Visual investiga los sincronismos entre la música y las formas geométricas, como en las obras Rhythmus 21 (1921) de Hans Richter y Symphonie diagonale (1924) de Viking Eggeling. Junto con los futuristas en los primeros años del siglo XX, artis- 
tas como el alemán Hans Stoltenberg y el finlandés Leopoldo Survage pintan directamente sobre el celuloide. También en los años 50, el neozelandés Len Lye utilizó técnicas de animación experimental en su obra Free Radicals (1958) rasgando el celuloide para generar líneas de luz dinámicas. Norman McLaren es otro artista clave de la manipulación directa de la imagen y el sonido sobre el celuloide como en su obra Loops (1940). En los años 70, el español Javier Aguirre construye la estructura de su película Espectro siete (1970), a partir de una partitura musical que traduce a color basándose el efecto Döppler. Son muchos los artistas que podemos destacar como Walter Ruttman, Oskar Fischinger, Len Lye, Harry Smith, los hermanos Whitney, Jordan Belson, Chris Larkee, Bärbel Neubauer, Larry Cuba y Norman McLaren entre otros (Moritz 1997; Wheeler 2002).

El desarrollo tecno-científico de dispositivos de análisis y visualización de sonido, como el osciloscopio y el espectrograma (Potter 1947) influyó en artistas, como la cineasta experimental estadounidense Mary Ellen Bute. En 1950 empezó a usar patrones de un osciloscopio como elementos principales para sus películas. Abstronic (1954) (ver figura 2) y Mood Contracts (1956), son dos de los trabajos en los que usaría imágenes de osciloscopio. Aunque Norman McLaren ya había usado anteriormente dicha técnica en su película Around is Around de 1950 (Moritz 1996).

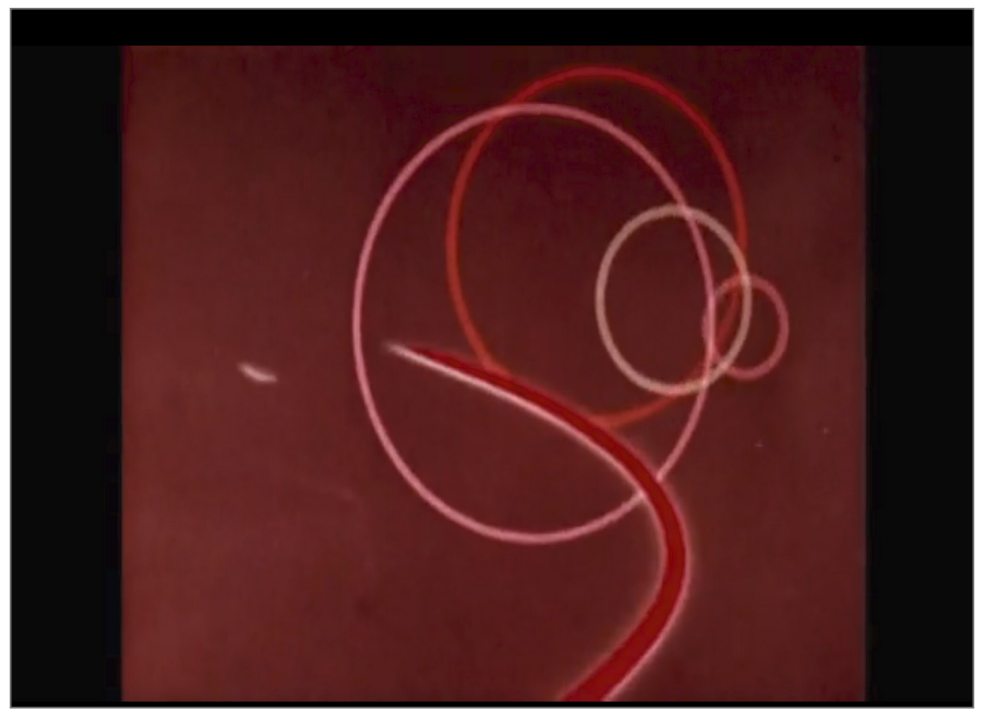

Fig. 2. Fotograma de Abstronics, Bute. $1952^{1}$ 
El cine abstracto y experimental de la primera mitad del siglo $X X$ marca la nueva dirección de las relaciones entre la imagen y el sonido. Como con los instrumentos visuales su desarrollo ha continuado hasta nuestros días. De la Música Visual podemos destacar:

- El sonido y la imagen se almacenan en el mismo medio y por lo tanto se pueden sincronizar.

- La estética que se plantea para visualizar el sonido es la ausencia de figuración. El sonido se ve mediante figuras geométricas y texturas que evolucionan en el tiempo, donde sus movimientos se formalizan a través de conceptos musicales de orquestación, contrapunto, ritmo o armonía.

- La forma con la que se crean imágenes es pintando o colocando máscaras directamente sobre el celuloide, o fotografiando cuadro por cuadro, la sincronización con el sonido se establece mirando físicamente la pista de sonido o realizando cálculos. Incluso el sonido se puede pintar.

- Se empiezan a usar visualizaciones directas del sonido usando imágenes generadas directamente mediante un osciloscopio.

- Con el cine se pierde la idea de tiempo real, que tenían los instrumentos visuales, aunque con la llegada del video y posteriormente los sistemas informáticos se volverá a recuperar.

Para una profundización en el campo de la Música Visual se pueden consultar los trabajos de Brougher (2005), Daniels (2009), Kock (1971) y García (2016a).

\section{GENERACIÓN SINTÉTICA DE IMAGEN}

En los años sesenta surge el videoarte y la videoinstalación que retoman la tradición del cine experimental con medios electrónicos. La inmediatez de resultados proporciona el entorno adecuado para la investigación de nuevas formas de presentar la imagen y el sonido.

Gary Hill dedica prácticamente todo su trabajo a investigar en las relaciones del lenguaje y la imagen. Recogiendo la herencia dejada por cineastas como Einsenstein, Fritz Lang o MacLaren que ya introdujeron la palabra en sus películas, Hill establece las bases de los poemas audiovisuales. En los trabajos 
de Hill, las imágenes y las palabras se acercan y se estructuran con la misma esencia que la poesía dicta los entresijos de los sentimientos.

Artistas como Nan June Paik y los Vasulka, entre otros muchos, experimentaron con sintetizadores de vídeo analógicos para generar imagen y sonido (Rekalde 1995; Baigorri, 2004; Bonet, 2010).

Woody y Steina Vasulka comenzaron a trabajar con ondas generadas por sintetizadores de sonido tratando que influyeran en la pantalla de un televisor. Nan June Paik empezó manipulando las imágenes electrónicas con imanes. Esta necesidad de procesamiento de la imagen electrónica hace que los artistas e ingenieros se propongan la elaboración de dispositivos capaces de generar y manipular imagen electrónica.

Estos dispositivos subrayaron la relación interdisciplinar arte-tecnología. El investigador y artista Dan Sandin en 1970 diseñó y construyó el video-sintetizador Image Processor, que podía manipular la señal de vídeo en tiempo real. En 1968, el artista Stephen Beck construyó el primer visualizador electrónico, Direct Video Zero, que, a partir de sonido generado por un sintetizador, producía imagen sintética. En 1976 el diseñador Robert Brown fabricó el primer visualizador electrónico comercial, el Atari Video Music. Era un equipo que se conectaba con el amplificador del equipo de sonido del cual tomaba la señal de sonido y su salida se conectaba con el televisor. Las imágenes resultantes eran figuras geométricas sincronizadas con la música

De este periodo podemos destacar la importancia que supuso la generación automática de imágenes a través de los videosintetizadores, incluso se realizan los primeros experimentos para tratar de ver el sonido. Todas las técnicas de manipulación de sonido electrónico son llevadas también a la imagen. Se retoma el concepto de directo y de tiempo real, el videosintetizador puede crear imagen y manipularse en tiempo real. La imagen y el sonido electrónico hablan el mismo lenguaje, nunca los dos medios habían estado tan cerca. El sonido se ve abstracto y la imagen se sincroniza de forma automática con el sonido. De nuevo todas estas tendencias llegan hasta nuestros días.

Para una profundización en el campo de la videocreación se puede consultar el trabajo que realizó Televisión Española con la serie "El Arte del Video" (Pérez 1991), así como Rosseti (2011) y Benavides (2010). Para una revisión del videoarte en España se puede consultar Sedeño (2011). 


\section{POPULARIZACIÓN DE LA VISUALIZACIÓN DE LA MÚSICA}

En los años setenta y herederos de las estéticas del cine experimental y el videoarte, surge de la cultura popular el género del Videoclip Musical, como producto comercial orientado a la promoción de grupos musicales (Sánchez 2009).

Martin Sánchez (2011) propone una clasificación del género que abraca desde estilos que simulan coreografías, al estilo de los musicales cinematográficos, estilos basados en la representación televisiva o estilos experimentales, por citar algunas de sus tendencias. Además, cada género musical establecerá con el tiempo unos cánones característicos. Una característica que marca la estética del videoclip es la ausencia de reglas fijas y la apropiación de todos los formatos, lenguajes y modelos audiovisuales, importados del cine, televisión, arte o animación. Desde su aparición ha atraído a cineastas, artistas y diseñadores de reconocido prestigio que han realizado propuestas muy interesantes, Laurie Anderson, John Sanborn, Andy Warhol, Martin Scorsese, Spike Jonze, Michel Gondry, son algunos ejemplos

Del videoclip podemos destacar que toma su estética de todas las corrientes audiovisuales, estableciendo una hibridación y un mestizaje entre ellas. No obstante, un aspecto muy importante es la popularización que supone la visualización de la música, con o sin músicos, con el consiguiente enriquecimiento cultural que verá sus frutos a finales del siglo $X X$ y principios del XXI con una gran cantidad de trabajos sin ánimos comerciales. Por último, resaltar que el objetivo artístico principal es acompañar visualmente a la música, estableciendo una clara primacía del sonido sobre la imagen.

Para una profundización en el campo del videoclip se pueden consultar los trabajos de Sanchez (2009) y Selva (2012).

\section{LA ERA DIGITAL}

Con la expansión de la tecnología digital se abre un nuevo marco para reformular la herencia analógica y plantear nuevos retos en el campo de visuali- 
zación. Los sistemas digitales se establecen como nexo y punto de conexión entre las diferentes corrientes surgidas a raíz de las tecnologías analógicas, siendo los conceptos de multimedia, interactividad y tiempo real los encargados de liar y expandir definitivamente al sonido y a la imagen.

Esta nueva etapa plantea un nuevo paradigma tecnológico, la era digital, no se trata de un nuevo formato sino de una nueva visión de la tecnología tan importante como lo fue la revolución industrial a principios del siglo pasado. No solo revoluciona el campo de imagen y sonido, sino prácticamente en mayor o menor medida todas las áreas de conocimiento humanista y sobre todo científico.

La era digital en la que estamos inmersos, es un tiempo de lenguajes, y los lenguajes formales, numéricos o matemáticos son la esencia de los ordenadores, donde casi todo tiene que ver con protocolos, interpretaciones, compilaciones o traducciones de unos lenguajes numéricos en otros. $Y$ es en este contexto cuando las imágenes y los sonidos más cerca están puesto que se representan internamente en un mismo lenguaje, el lenguaje de los números. De esta forma mediante los lenguajes de programación de los ordenadores podemos generar imágenes directamente influenciadas por los números del sonido e incluso genera sonidos directamente influenciados por los números de la imagen (García 2016b). Siguiendo esta línea de investigación desde finales de los 80 hasta nuestros días encontramos gran cantidad de propuestas de artistas como Golan Levi, Zachary Lieberman, Robert Henke, Alva Noto, Ryoji Ikeda, Karl Kliem, Kalus Obermaier, Craig Allan, Robert Hodgin, Robin Fox, Laboratorio de Luz, colectivo PDP11, Markus Heckman, Daniel Palacios, Fredik Olofsson que, entre otros, trabajan en el campo de la visualización del sonido.

\section{ARCHIVOS Y RECURSOS EN LA RED}

Actualmente las relaciones entre la imagen y el sonido es un campo muy activo debido a que se están realizando convergencias tanto del campo del sonido hacia la visualización, como del campo de las artes visuales hacia el sonido. Una muestra de ello es la gran cantidad archivos y recursos activos en la web, de los que podemos destacar: Center of Visual Music, lota Center, See this Sound y Visual Music Archive, como verdaderos contenedores de información 
sobre el campo de visualización, donde podemos encontrar desde artistas precursores del género hasta las más novedosas tendencias actuales.

El Center of Visual Music ${ }^{2}$ (CVM) es un archivo fílmico, sin ánimo de lucro dedicado a la música visual, animación experimental y cine abstracto, con base en Los Angeles. El centro gestiona obra, libros, revistas y catálogos de artistas como Richard Baily, Jordan Belson, John Bachanan, Scott Draves, Wiking Eggeling, Oskar Fischinger, Ken Jenkins, Len lye, Neubauer, Semiconductor, Jeff Perkins, Man Ray, Jurgen Reble, Richard Reeves, Hans Richter, Elias Romero, Walter Ruttmann, Robert Seidel, Paul Sharits, George Stadnik, Stan VanDerBeek, Joshua White, Thomas Wilfred entre otros. Este centro presenta una línea clásica pero muy amplia del campo de visualización. Mantiene un sistema de socios o miembros del centro, de manera que pueden publicitar sus artículos, consultar la videoteca, descuentos en libros y una serie de beneficios adicionales.

En una línea similar al CVM, encontramos el lota Center ${ }^{3}$ especializado en cine abstracto, animación y películas de artistas de la costa oeste de Estados Unidos de América. Activo desde 1994 abarca desde conservación hasta investigación y exhibición de obras. Como ocurre en el CVM adolece de la promoción de obras con tecnología más actual.

El archivo web See This Sound ${ }^{4}$ arranca en 2009 como un proyecto para Linz 2009, capital de cultura europea, realizado en estrecha colaboración con Lentos Art Museum Linz ${ }^{5}$ y Ludwig Boltzmann Institute Medien.Kunst.Forschung ${ }^{6}$. Actualmente lo mantiene y actualiza la Academy of Visual Arts Leipzig. El proyecto aborda también exposiciones y congresos a cerca de las conexiones entre imagen y sonido en los ámbitos del arte, medios audiovisuales y percepción. El sitio web está organizado por una serie de temas: cine abstracto, visuales en tiempo real, sonidificación, sinestesia..., para cada uno de los temas se ha desarrollado un artículo amplio y una relación de artistas y obras relacionados con el tema. Es bastante completo y abarca desde los orígenes hasta la actualidad.

Por último nos gustaría destacar el archivo web Visual Music Archive ${ }^{7}$. Se trata de una colección no institucional, y como apuntan desde El propio archivo altamente subjetiva de trabajos inspirados en el amplio campo de la Música Visual. A nuestro juicio representa la mejor y mayor recopilación de material relacionado con las intersecciones entre el sonido y la imagen. Desde autores 
y proyectos clásicos hasta las últimas tendencias. Adicionalmente hay referencias a prácticamente toda la literatura del campo.

\section{CONCLUSIONES}

La visualización del sonido siempre ha estado íntimamente relacionada con la tecnológica y los movimientos culturales de cada época. Es un claro ejemplo de relación entre arte y tecnología puesto que su propia naturaleza es tanto tecnológica como artística, no se trata de llevar el arte hacia la tecnología o la tecnología hacia el arte sino que su más pura expresión atraviesa inequívocamente los dos campos del saber. Resulta interesante resaltar como artistas de todas las épocas se sienten seducidos por la naturaleza visual del sonido, sin ser conscientes de la gran tradición histórica que existe. El cruce de los sentidos es una materia de largo recorrido y cada nueva generación de artistas incorpora nuevas aportaciones íntimamente relacionadas con los lenguajes que surgen y surgirán con los avances tecnológicos.

A través de este repaso histórico hemos visto que los instrumentos visuales e instalaciones audiovisuales aportan la interactividad, tiempo real y la idea de sinestesia, el cine experimental en su vertiente de música visual define la estética abstracta como visualización propia del sonido e incorpora las estructuras musicales en la composición visual, el videoarte incorpora el concepto de procesamiento como elemento fundamental en desarrollo creativo y el videoclip aporta fundamentalmente la popularización de la estrecha relación entre el sonido y la imagen. En este panorama, los sistemas informáticos ejercen de crisol integrando todos estos elementos, propiciando la aparición de nuevas propuestas como las instalaciones y performances multimedia y el vjing o live cinema.

Somos conscientes que nuestra revisión histórica solo llega hasta los inicios de la era digital, y es justo en esta época donde nos encontramos con las condiciones tecnológica más idóneas para la búsqueda de nuevos lenguajes que establezcan un universo común entre el sonido y la imagen. También somos conscientes que este breve repaso ha dejado, que no olvidado, a muchos artistas que han contribuido de forma relevante a este extenso campo. 
Por último como trabajo futuro nos gustaría revisar en profundidad esa última etapa, sobre la que en este artículo solo hemos pasado someramente, en la que nos encontramos inmersos, y donde las herramientas de construcción de las relaciones entre sonido e imagen son los lenguajes de programación.

\section{Referencias}

Baigorri Ballarín, Laura. 2004. Vídeo, primera etapa: El vídeo en el contexto social y artístico de los años 60/70. Madrid: Brumaria

Brougher, Kerry, Jeremy Strick, Ari Wiseman \& Judith Zilczer. 2005. Visual music: Synaesthesis in art and music since 1900. Los Angeles CA: The Museum of Contemporary Art

Daniels, Dieter. 1997. "Art and media in the XX. Century". En The Age of Modernism-Art in the 20th Century, catalogue for the exhibition at Martin-Gropius-Bau Berlin 1997, 553-64. Stuttgart: Gerd Hatje

García Miragall, Carlos Manuel. 2016. "Generación de imagen sintética en tiempo real basada en muestras de sonido digitalizado en el campo del arte digital". Tesis Universitat Politècnica de València

— \& Francisco Sanmartin Piquer. 2016. "De números a números: Visualización del sonido por métodos relacionales de muestreo en directo". AusArt 4(1): 105-17

Kandinskiï, Vasilii Vasil'evich. (1911) 1996. De lo espiritual en el arte. Traducción del alemán de Genoveva Dieterich. Barcelona: Paidós

Kaper, Hans G., Elizabeth Wiebel \& Sever Tipei. 1999. "Data sonification and sound visualization". Computing in Science and Engineering 1(4):48-58

Levin, Golan. 2000. "Painterly interfaces for audiovisual performance". Tesis MIT Media Laboratory (M.S. Thesis)

Malinowski, Stephen. 2016. "Stephen Malinowski and the Music Animation Machine". Página web del artista. http://www.musanim.com/ [Última modificación 6 abr.].

Martín Sánchez, Gonzalo. 2010. La música y la evolución de la narración audiovisual: la narración audiovisual en los videos musicales. Badajoz: Abecdario

McDonnell, Maura. 2007. "Visual music". eContact! 15(4). https://econtact.ca/15_4/mcdonnell_visualmusic.html

Moritz, William. 1996. "Mary Ellen Bute: Seeing sound". Animation World 1(2). https://www. awn.com/mag/issue1.2/articles1.2/moritz1.2.html

- . 1997. "The dream of color music, and machines that made it possible". Animation World 2(1). https://www.awn.com/mag/issue2.1/articles/moritz2.1.html

Peacock, Kenneth. 1988. "Instruments to perform color-music: Two centuries of technological experimentation". Leonardo 21(3): 397-406

Pérez Ornia, José Ramón. 1991. El arte del video: Introducción a la historia del video experimental. Barcelona: Serval.

Potter, Ralph K., George A. Kopp \& Harriet C. Green. 1947. Visible speech. New York: Van Nostrand 
Rosseti Ricapito, Laura. 2011. Videoarte: Del cine experimental al arte total. México DF: UAM

Sánchez López, Juan Antonio et al. 2009. Historia, estética e iconografía del videoclip musical. Málaga: Universidad de Málaga

Sedeño Valdellós, Ana. 2011. Historia y estética del videoarte en España. Sevilla: Comunicación Social.

Selva Ruiz, David. 2012. "La visualización de la música en el videoclip". Ámbitos 21(A): 101-15

Rekalde Izagirre, Josu. 1995. Vídeo, un soporte temporal para el arte. Bilbao: Univresidad del País Vasco

Sapp, Craig Stuart. 2001. "Harmonic visualizations of tonal music". Proceedings of the 2001 International Computer Music Conference. 423-30

Smith, Sean M. \& Williams, Glen N. 1997. "A visualization of music". Visualization '97 Proceedings: 499-502

Wallace Rimington, Alexander. 1912. Color music: The art of mobile color. London: Hutchinson

Kock, Winston E. 1971. Seeing sound. New York: Wiley-Interscience

Bonet, Eugeni, et al. (1980) 2010. En torno al vídeo. Coordinación Fito Rodríguez Bornaetxea \& Natxo Rodríguez Arkaute. Leioa: Universidad del País Vasco

\section{Notas}

*Este trabajo es resultado del proyecto de investigación de la Universitat Politècnica de València financiado por la Generatitat Valenciana con referencia GV/2017/028.

${ }^{1}$ The Internet Archive. https://archive.org/details/1952MARYELLENBUTTEABSTRONICDVD [Acceso 23 oct. 2017].

${ }^{2}$ Center of Visual Music. http://www.centerforvisualmusic.org [Acceso 23 oct. 2017].

${ }^{3}$ lota Center. $h$ ttp://www.iotacenter.org [Acceso 23 oct. 2017].

${ }^{4}$ See This Sound. http://www.see-this-sound.at [Acceso 23 oct. 2017].

${ }^{5}$ Lentos Art Museum. http://www.lentos.at/html/de/index.aspx [Acceso 23 oct. 2017].

${ }^{6}$ Ludwig Boltzmann Institute Medien Kunst Forschung. http://www.lentos.at/html/de/index.aspx [Acceso 23 oct. 2017].

${ }^{7}$ Visual Music Archive. http://visualmusicarchive.org [Acceso 23 oct. 2017]. 